\title{
24-Month Efficacy and Safety Results from Japanese Patients in the IMPERIAL Randomized Study of the Eluvia Drug-Eluting Stent and the Zilver PTX Drug-Coated Stent
}

\author{
Osamu Iida $^{1}$ (D) Masahiko Fujihara ${ }^{2}$ - Daizo Kawasaki ${ }^{3} \cdot$ Shinsuke Mori $^{4}$ • \\ Hiroyoshi Yokoi $^{5}$ - Akira Miyamoto ${ }^{6}$ Kimihiko Kichikawa ${ }^{7} \cdot$ Masato Nakamura $^{8}$. \\ Takao Ohki ${ }^{9} \cdot$ Juan Diaz-Cartelle $^{10} \cdot$ Stefan Müller-Hülsbeck $^{11} \cdot$ William A. Gray $^{12}$ • \\ Yoshimitsu Soga ${ }^{13}$
}

Received: 2 April 2021 / Accepted: 15 June 2021 / Published online: 7 July 2021

(C) The Author(s) 2021

\begin{abstract}
Purpose The purpose of the study is to report 24-month efficacy and safety results for the Japanese patient cohort in a prospective randomized controlled trial (RCT) of drugeluting stent (DES) use for peripheral artery disease.

Materials and methods Patients in the global IMPERIAL RCT had femoropopliteal lesions treated with either the Eluvia DES (Boston Scientific, Marlborough, MA, USA) or the Zilver PTX drug-coated stent (Cook Medical,
\end{abstract}

Osamu Iida

iida.osa@gmail.com

Masahiko Fujihara

masahikofujihara@yahoo.co.jp

Daizo Kawasaki

kawasaki@omichikai.or.jp

Shinsuke Mori

hello_morisun@yahoo.co.jp

Hiroyoshi Yokoi

hiroyokoi@circus.ocn.ne.jp

Akira Miyamoto

Miyamoto_01234@yahoo.co.jp

Kimihiko Kichikawa

kkichika@naramed-u.ac.jp

Masato Nakamura

masato@oha.toho-u.ac.jp

Takao Ohki

takohki@msn.com

Juan Diaz-Cartelle

Juan.Diaz-Cartelle@bsci.com

Stefan Müller-Hülsbeck

muehue@diako.de

William A. Gray

GrayW@MLHS.org
Bloomington, IN, USA). At 24 months, assessments included duplex ultrasound imaging for core laboratory vessel patency measurement, target lesion revascularization (TLR) rates, and clinical outcome measures.

Results The Japanese cohort included 84 patients (56 treated with Eluvia and 28 with Zilver PTX). The clinically driven TLR rates were 5.6\% (3/54) and 18.5\% (5/27) for patients treated with Eluvia and Zilver PTX, respectively (difference $-13.0 \%$, 95\%CI -28.8, 2.9\%; $p=0.11$ ). The

Yoshimitsu Soga

soga@circulation.jp

1 Kansai Rosai Hospital, Amagasaki, Hyogo, Japan

2 Kishiwada Tokushukai Hospital, Osaka, Japan

3 Morinomiya Hospital, Osaka, Japan

4 Saiseikai Yokohama-City Eastern Hospital, Yokohama, Japan

5 Fukuoka Sanno Hospital, Fukuoka, Japan

6 Takatsu General Hospital, Kawasaki, Japan

7 Nara Medical University Hospital, Kashihara, Japan

8 Toho University Ohashi Medical Center, Tokyo, Japan

9 The Jikei University Hospital, Tokyo, Japan

10 Boston Scientific, Marlborough, MA, USA

11 DIAKO Krankenhaus GmbH Flensburg, Flensburg, Germany

12 Lankenau Heart Institute, Wynnewood, PA, USA

13 Kokura Memorial Hospital, Kitakyushu, Japan 
Kaplan-Meier estimates for freedom from clinically driven TLR at 24 months were $94.3 \%$ for patients who received Eluvia and $80.4 \%$ for those who received Zilver PTX (log rank $p=0.05)$, and for primary patency they were $88.5 \%$ and $80.4 \%$, respectively ( $\log$ rank $p=0.28)$. Mortality rates were $5.6 \% \quad(3 / 54)$ and $11.1 \% \quad(3 / 27) ; p=0.39$. Rutherford classification improved by at least one category without TLR for $91.8 \%(45 / 49)$ and $68.2 \%(15 / 22)$ of patients $(p=0.03)$. Walking impairment score improvements were sustained over time.

Conclusion The results at 24 months support the efficacy and safety of DES in Japanese patients, with sustained clinical improvements and numerically fewer reinterventions for those treated with Eluvia.

Clinical trial Registration Clinicaltrials.gov identifier NCT02574481.https://clinicaltrials.gov/ct2/show/

NCT02574481

Level of Evidence EBM Level III; cohort analysis of randomized trial.

Keywords Drug-eluting stent · Paclitaxel .

Peripheral arterial disease $\cdot$ Superficial femoral artery

- Vascular patency

\section{Introduction}

The ability of drug-eluting endovascular treatment of femoropopliteal disease to reduce the need for reinterventions has been well described, particularly in the short term and for Caucasian populations [1-6]. Longer-term prospective data are important to characterize the outcomes expected for patients over time [7-10], and large randomized studies provide opportunity to explore clinical outcomes over time for various patient cohorts [11].

The IMPERIAL randomized controlled study [10, 12] is a comparison of the durable-polymer-coated Eluvia DES (Boston Scientific, Marlborough, MA, USA) and polymerfree Zilver PTX drug-coated stent (Cook Corporation, Bloomington, IN, USA). Among global randomized patients, Eluvia DES demonstrated superior efficacy at 1 year [12] with favorable outcomes sustained at 2 years [10].

Peripheral artery disease (PAD) is highly prevalent in Japan [13], and identifying effective treatments is important in this population. One-year results in the cohort of patients from Japan showed outstanding patency and safety [14], and we sought to determine whether the 2-year outcomes for Japanese patients were likewise reflective of the overall trial findings. This report presents the primary patency, freedom from clinically driven target lesion revascularization (CD-TLR), patient outcome assessments, and safety for Japanese patients in the IMPERIAL randomized trial through 24 months.

\section{Materials and Methods}

\section{Study Population}

IMPERIAL randomized trial methods were reported previously [12]. Eligible patients had stenotic or occlusive femoropopliteal artery lesions (total length 30-140 mm) and Rutherford category 2, 3, or 4 symptoms at presentation. Informed consent was required from all study patients. Patients were randomly assigned to treatment with either Eluvia DES or Zilver PTX in a 2:1 ratio. Of the 465 patients in the global randomized trial, 84 were enrolled across 10 Japanese sites $(n=56$ Eluvia, $n=28$ Zilver PTX; $18 \%$ of the overall study sample).

\section{Assessments and Definitions}

Scheduled assessments at 24 months (730 \pm 30 days) post-procedure included the following: duplex ultrasound (DUS) imaging for vessel patency measurement by the ultrasound core laboratory (VasCore, Boston, MA, USA), Rutherford category for clinical improvement, ankle-brachial index (ABI), the Walking Impairment Questionnaire (WIQ), EQ-5D health-related quality of life assessment, and antiplatelet medication use. Japanese translations of the WIQ and EQ-5D were administered at Japanese sites. An independent Clinical Events Committee adjudicated TLR, target limb amputation, stent thrombosis, and death reported through 24-month follow-up.

CD-TLR was defined as a reintervention within $5 \mathrm{~mm}$ proximal or distal to the original treatment segment for angiographic diameter stenosis $\geq 50 \%$ in the presence of recurrent symptoms (i.e., increase in Rutherford class by 1 or more) or ankle-brachial index decrease in at least 0.15 or $20 \%$ compared with post-treatment in the treated segment. Primary patency was defined for target stented segments as core-lab evaluated peak systolic velocity ratio $\leq 2.4$ and without CD-TLR or bypass of the target lesion.

\section{Statistical Analysis}

These cohort analyses were not powered for hypothesis testing and thus are considered exploratory. Event rates are reported for safety measures adjudicated by the Clinical Events Committee, and $95 \%$ confidence intervals were calculated around the difference between intervention groups. Statistical significance testing of categorical 
variables was performed with two-sided Fisher's exact test or Chi-square test. For continuous variables, $p$-values are from 2-sided $t$-tests. Kaplan-Meier curves for freedom from CD-TLR and primary patency were generated with standard errors; log rank $p$-values were calculated. KaplanMeier patency estimates were based on the time to event of CD-TLR up to 730 days and duplex ultrasound data at 24 months. Statistical analyses were performed with Statistical Analysis Software, version 9.2 or later (SAS Institute Inc., Cary, North Carolina, USA).

\section{Results}

\section{Patients}

Baseline characteristics of the 84 Japanese patients enrolled in IMPERIAL are summarized in Table 1. Mean lesion length was $91.8 \pm 38.0 \mathrm{~mm}$ for patients treated with Eluvia and $87.4 \pm 41.7 \mathrm{~mm}$ for patients treated with Zilver PTX. Moderate or severe calcification was present in $60.7 \%$ and $82.1 \%$ of patients, respectively. Seventy-one patients completed the 24-month visit, and 3 patients in each treatment arm died prior to the visit.

\section{Safety and Efficacy}

Events adjudicated by the Clinical Events Committee are shown in Table 2. As shown in the table, the 24-month CDTLR rate for patients treated with Eluvia was less than onethird that of patients treated with Zilver PTX. KaplanMeier estimates of freedom from CD-TLR and primary patency are shown in Figs. 1 and 2, respectively. The Kaplan-Meier estimate for freedom from CD-TLR at 24 months was $94.3 \%$ for patients who received Eluvia and $80.4 \%$ for those who received Zilver PTX (log rank $p=0.05$; Fig. 1).

Kaplan-Meier estimates of primary patency at 24 months were $88.5 \%$ and $80.4 \%$ for Eluvia and Zilver PTX-treated patients, respectively (log rank $p=0.28$; Fig. 2).

No new stent thrombosis was reported between 12- and 24-month follow-up. One patient in the Eluvia arm had stent thrombosis (Table 2), and TLR reported prior to 12-month follow-up as described previously [14]. DUS

Table 1 Baseline characteristics of IMPERIAL patients enrolled in Japan

\begin{tabular}{|c|c|c|c|}
\hline & Eluvia $(N=56)$ & Zilver PTX $(N=28)$ & $p$ \\
\hline Age (y) & $73.7 \pm 7.7$ & $74.3 \pm 7.3$ & 0.71 \\
\hline Male & $76.8 \%(43 / 56)$ & $75.0 \%(21 / 28)$ & 0.86 \\
\hline \multicolumn{4}{|l|}{ Smoking history } \\
\hline Current & $16.1 \%(9 / 56)$ & $25.0 \%(7 / 28)$ & 0.33 \\
\hline Previous & $62.5 \%(35 / 56)$ & $60.7 \%(17 / 28)$ & 0.87 \\
\hline Medically treated diabetes mellitus & $53.6 \%(30 / 56)$ & $53.6 \%(15 / 28)$ & 1.00 \\
\hline $\mathrm{ABI}$ & $0.7 \pm 0.2$ & $0.7 \pm 0.2$ & 1.00 \\
\hline \multicolumn{4}{|l|}{ Arterial Segments } \\
\hline Ostial & $1.8 \%(1 / 56)$ & $0.0 \%(0 / 28)$ & $1.00^{\mathrm{a}}$ \\
\hline Proximal superficial femoral artery & $17.9 \%(10 / 56)$ & $14.3 \%(4 / 28)$ & $0.77^{\mathrm{a}}$ \\
\hline Mid-superficial femoral artery & $71.4 \%(40 / 56)$ & $71.4 \%(20 / 28)$ & 1.00 \\
\hline Distal superficial femoral artery or proximal popliteal artery & $50.0 \%(28 / 56)$ & $60.7 \%(17 / 28)$ & 0.35 \\
\hline Lesion length (mm) & $91.8 \pm 38.0$ & $87.4 \pm 41.7$ & 0.63 \\
\hline Reference vessel diameter (mm) & $5.1 \pm 0.8$ & $5.0 \pm 0.7$ & 0.49 \\
\hline \multicolumn{4}{|l|}{ Calcification } \\
\hline None/mild & $39.3 \%(22 / 56)$ & $17.9 \%(5 / 28)$ & 0.05 \\
\hline Moderate & $32.1 \%(18 / 56)$ & $50.0 \%(14 / 28)$ & 0.11 \\
\hline Severe & $28.6 \%(16 / 56)$ & $32.1 \%(9 / 28)$ & 0.74 \\
\hline$\%$ Diameter stenosis & $79.9 \pm 14.0$ & $74.9 \pm 14.3$ & 0.12 \\
\hline $50 \%-99 \%$ & $80.4 \%(45 / 56)$ & $82.1 \%(23 / 28)$ & 0.84 \\
\hline $100 \%$ (Occlusion) & $19.6 \%(11 / 56)$ & $17.9 \%(5 / 28)$ & 0.84 \\
\hline
\end{tabular}

Continuous data are presented as the means \pm standard deviation; categorical data are given as the percentage (count). All lesion characteristics are as reported by the angiographic core laboratory

${ }^{a} p$-values from 2-sided Fisher's exact test 
Table 2 Events adjudicated by the Clinical Events Committee through 24 months ${ }^{\mathrm{a}}$

\begin{tabular}{|c|c|c|c|c|}
\hline & Eluvia $(n=56)$ & Zilver PTX $(n=28)$ & Difference $[95 \% \mathrm{CI}]$ & $p^{\mathrm{b}}$ \\
\hline All deaths & $5.6 \%(3 / 54)$ & $11.1 \%(3 / 27)$ & $-5.6 \%[-18.9 \%, 7.8 \%]$ & 0.39 \\
\hline Target lesion revascularization $^{c}$ & $5.6 \%(3 / 54)$ & $18.5 \%(5 / 27)$ & $-13.0 \%[-28.8 \%, 2.9 \%]$ & 0.11 \\
\hline Target limb amputation & $0.0 \%(0 / 54)$ & $3.7 \%(1 / 27)$ & $-3.7 \%[-10.8 \%, 3.4 \%]$ & 0.33 \\
\hline Stent thrombosis & $1.9 \%(1 / 54)$ & $0.0 \%(0 / 27)$ & $1.9 \%[-1.7 \%, 5.4 \%]$ & 1.00 \\
\hline
\end{tabular}

${ }^{a}$ The CEC-adjudicated denominator is based on 1) subjects with CEC-adjudicated events (i.e., any death, target lesion/vessel revascularization, target limb amputation, stent thrombosis) through 24 months and 2) subjects with no events but their follow-up time reach on (or beyond) the earliest visit window

${ }^{\mathrm{b}} \mathrm{P}$ values from 2-sided Fisher's exact test

${ }^{\mathrm{c}}$ All target lesion revascularizations met the criteria for "clinically driven;" i.e., a reintervention within 5 mm proximal or distal to the original treatment segment for angiographic diameter stenosis $\geq 50 \%$ in the presence of recurrent symptoms (i.e., increase in Rutherford class by 1 or more) or ABI decrease of at least 0.15 or $20 \%$ in the treated segment

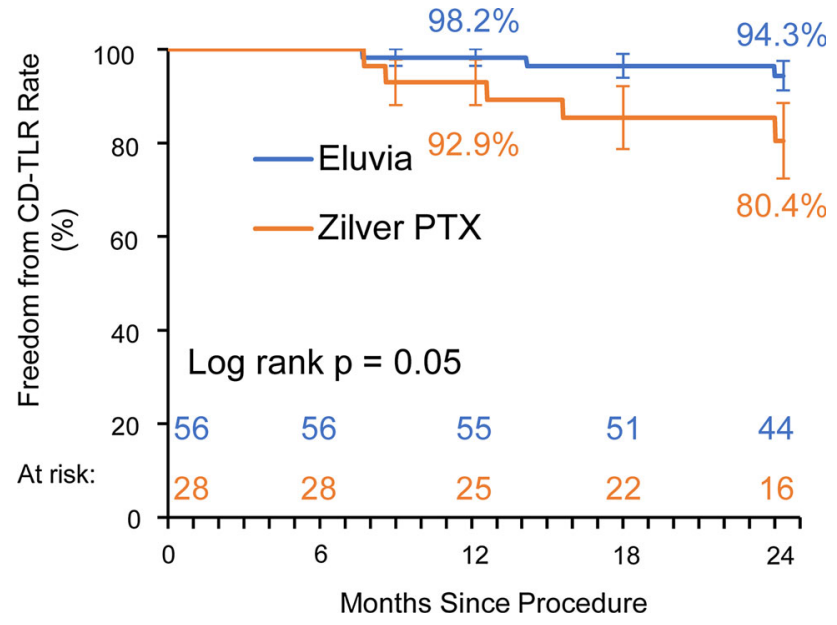

Fig. 1 Kaplan-Meier estimate of freedom from CD-TLR and standard errors

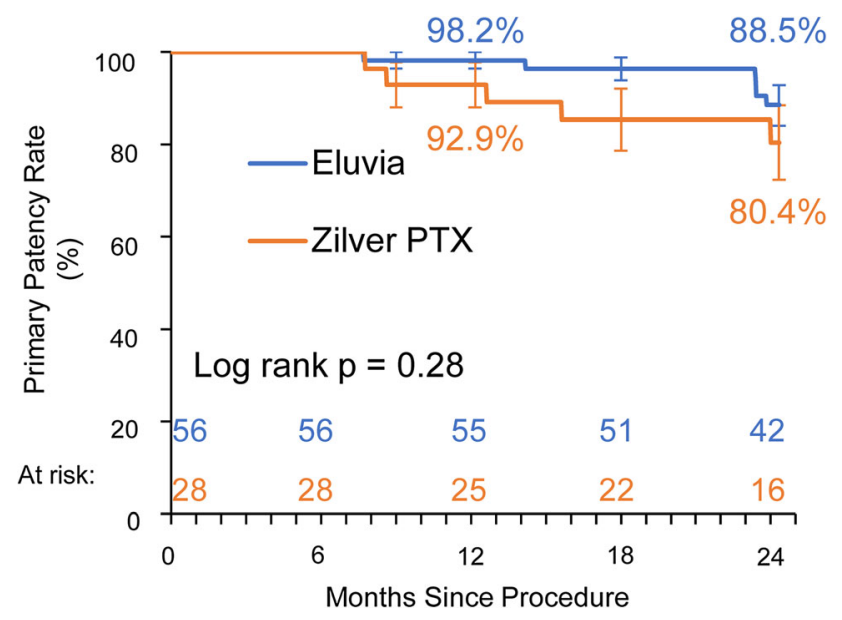

Fig. 2 Kaplan-Meier estimate of primary patency and standard errors

imaging at the patient's 24-month visit revealed stenosis proximal to the stent and stent occlusion.
All but one Japanese patient (Eluvia arm) who completed the 24-month visit had diagnostic radiography performed to examine stent integrity, and no new fractures were observed. One fracture had been identified in the Eluvia arm at the 12-month visit [14], and the stent was confirmed patent at 24 months; no associated complications or adverse events were reported.

\section{Antiplatelet Medication Use}

The study protocol required dual antiplatelet therapy for at least the first 60 days post-procedure. Use diminished over time with 24-month rates of $49.0 \%$ (24/49) and 40.9\% (9/ 22) for Eluvia and Zilver PTX, respectively, reported for dual antiplatelet therapy $(p=0.53)$. Antiplatelet monotherapy was recommended to continue through trial completion. At 24 months, acetylsalicylic acid use was reported by $75.5 \%$ (37/49) of Eluvia patients and $77.3 \%$ $(17 / 22)$ of Zilver PTX patients $(p=0.87)$.

\section{Clinical Outcomes}

The Rutherford category distribution is shown in Fig. 3. At 24 months, $89.8 \%$ (44/49) of patients treated with Eluvia and $72.7 \%(16 / 22)$ of patients treated with Zilver PTX presented with symptoms categorized as 0 or 1 , with primary sustained clinical improvement (i.e., improvement in Rutherford classification by one or more categories as compared with baseline and without TLR) for 91.8\% (45/ $49)$ of patients treated with Eluvia and $68.2 \%$ (15/22) of patients treated with Zilver PTX $(p=0.03)$.

ABI improvement was sustained through 24 months, with mean \pm SD values of $0.9 \pm 0.2$ and $0.9 \pm 0.1$ for patients treated with Eluvia and Zilver PTX, respectively. A total of $78.0 \%$ (39/50) of patients treated with Eluvia and $65.2 \%(15 / 23)$ of patients treated with Zilver PTX showed hemodynamic improvement $(p=0.25)$, defined as ABI 

distribution
Fig. 3 Rutherford category

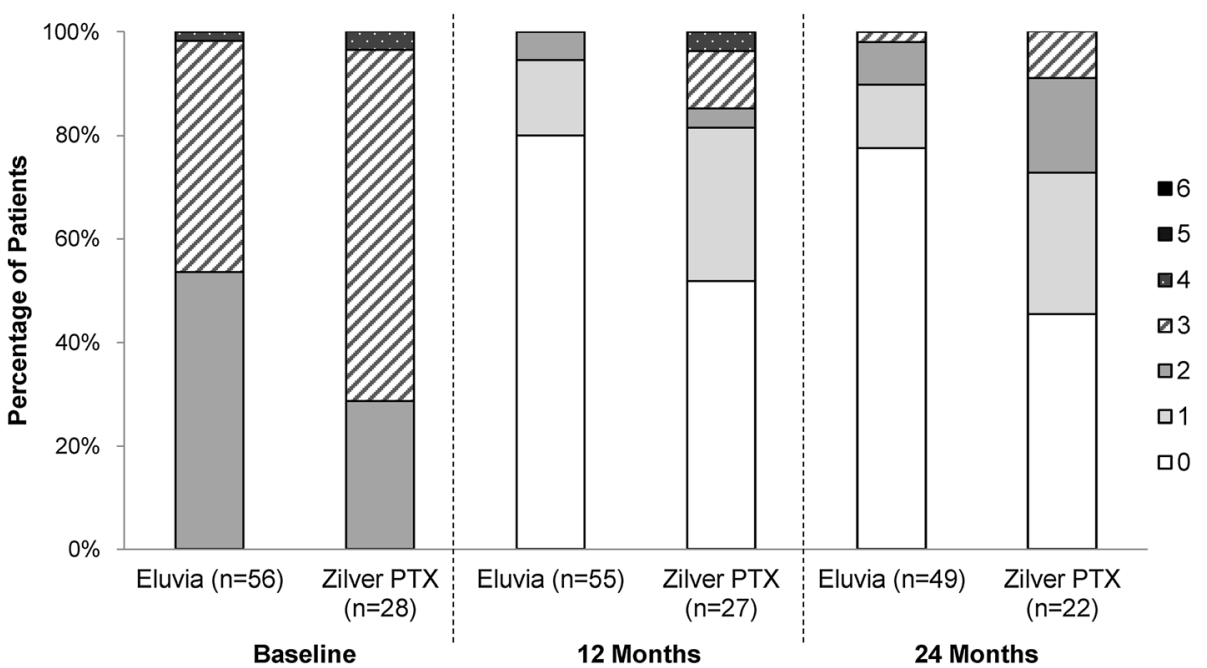

increase $\geq 0.10$ from baseline or achievement of $\mathrm{ABI}$ value $\geq 0.90$ without TLR.

Japanese patients in the study had sustained improvements in walking impairment scores over time (Table 3). The health-related quality of life measure showed that the distribution of patients experiencing problems with mobility or pain/discomfort shifted toward less severity (Online Resource 1). At 24 months, $40.8 \%$ and $27.3 \%$ of Eluvia- and Zilver PTX-treated patients $(p=0.27)$, respectively, showed improvement in mobility compared with baseline, and improvement in the pain/discomfort dimension was reported by $38.8 \%$ and $40.9 \%(p=0.86)$, respectively (Table 4).

\section{Discussion}

The 24-month results presented here support the efficacy and safety of DESs in Japanese patients. In this cohort, the 2-year reintervention rate for patients treated with Eluvia was approximately one-third that of patients treated with Zilver PTX and clinical improvements were sustained from 12 to 24 months. These results mirror those of the overall IMPERIAL RCT [10].

The literature on paclitaxel-containing endovascular therapy for Japanese patients with peripheral artery disease is not as extensive as that covering Caucasian populations. Favorable trends for maintaining patency and reducing reinterventions with drug-containing stents have been reported among Japanese patients [9, 11], but differences in lesion or patient characteristics or other study factors are potentially confounding and limit comparisons between studies. Ohki et al. [11] reported Kaplan-Meier estimates of freedom from TLR and primary patency of $96 \%$ and $80 \%$, respectively, for the small cohort of Japanese patients treated with Zilver PTX in the Zilver PTX RCT ( $n=25$; mean lesion length $58.8 \mathrm{~mm}, 38.5 \%$ with occlusions). Patients in the large $(N=905)$ Zilver PTX Japan postmarket surveillance study [9] had more complex lesions (mean lesion length $146 \mathrm{~mm}, 41.5 \%$ with occlusions), and the Kaplan-Meier estimates of freedom from CD-TLR and primary patency were $83.7 \%$ and $70.3 \%$, respectively, at 2 years. Together with the findings for Eluvia DES treatment reported here, which demonstrated Kaplan-Meier freedom from TLR of $94.3 \%$ and primary patency of $88.5 \%$ at 24 months, these results suggest that paclitaxelcontaining stents provide a clinical benefit to Japanese patients, with a more favorable trend observed for the polymer-based Eluvia DES.

Durability of DES outcomes is an important consideration given the landscape of other options for femoropopliteal treatment, such as drug-coated balloons. Iida et al. [15] reported 2-year primary patency of less than $80 \%$ among Japanese patients treated with drug-coated balloons who had lesion characteristics similar to those of the IMPERIAL patients (mean lesion length $91.5 \mathrm{~mm}, 16.2 \%$ with occlusions). The numerically better patency results reported here for patients treated with Eluvia suggest that DES may be appropriate to consider as a first choice, particularly for patients at greater risk of restenosis or more likely to require provisional stenting following balloonbased treatment [16].

The analyses reported here are limited by the small sample size and are unpowered for hypothesis testing. $P$ values for between-group comparisons are reported for reference. Although the cohort sample size is small, follow-up visit compliance was high with $97.3 \%$ of eligible patients (i.e., alive and not withdrawn) completing the 24-month visit to provide a comprehensive representation of the study cohort. Such exploratory analyses are valuable 
Table 3 Walking Impairment Questionnaire

\begin{tabular}{|c|c|c|c|c|c|}
\hline & Baseline & 1 Month & 6 Months & 12 Months & 24 Months \\
\hline \multicolumn{6}{|l|}{ Eluvia } \\
\hline Walking impairment & $58.48 \pm 32.78(56)$ & $92.41 \pm 17.79(56)$ & $90.63 \pm 15.49(56)$ & $84.55 \pm 21.78$ & $77.55 \pm 26.64$ \\
\hline Change from baseline & - & $33.93 \pm 34.19(56)$ & $32.14 \pm 34.28$ & $25.91 \pm 39.95(55)$ & $21.43 \pm 38.19$ \\
\hline$P^{\mathrm{a}}$ & - & $<.0001$ & $<.0001$ & $<.0001$ & 0.0003 \\
\hline Distance & $58.10 \pm 32.16(56)$ & $92.14 \pm 18.54(56)$ & $87.96 \pm 24.12(56)$ & $84.84 \pm 28.98$ & $80.54 \pm 33.33$ \\
\hline Change from baseline & - & $34.04 \pm 30.12(56)$ & $29.86 \pm 29.46(56)$ & $27.51 \pm 32.10$ & $23.16 \pm 34.65$ \\
\hline$P^{\mathrm{a}}$ & - & $<.0001$ & $<.0001$ & $<.0001$ & $<.0001$ \\
\hline Speed & $39.62 \pm 21.01(56)$ & $52.23 \pm 25.54(56)$ & $50.87 \pm 24.27(56)$ & $51.42 \pm 26.18$ & $51.71 \pm 31.13(49)$ \\
\hline Change from baseline & - & $12.62 \pm 22.34(56)$ & $11.26 \pm 23.85(56)$ & $11.56 \pm 25.35(55)$ & $12.91 \pm 26.44(49)$ \\
\hline$P^{\mathrm{a}}$ & - & $<.0001$ & 0.0008 & 0.0013 & 0.0013 \\
\hline Stair climbing & $56.85 \pm 32.73(56)$ & $74.26 \pm 29.17(56)$ & $73.44 \pm 30.09$ & $67.12 \pm 33.30$ & $72.96 \pm 34.23$ \\
\hline Change from baseline & - & $17.41 \pm 29.09$ & $16.59 \pm 31.73(56)$ & $9.54 \pm 30.55(55)$ & $14.88 \pm 33.07$ \\
\hline$P^{\mathrm{a}}$ & - & $<.0001$ & 0.0003 & 0.0243 & 0.0028 \\
\hline \multicolumn{6}{|l|}{ Zilver PTX } \\
\hline Walking impairment & $58.04 \pm 25.51$ & $84.82 \pm 23.90(28)$ & $73.21 \pm 32.58$ & $71.30 \pm 33.76(27)$ & $75.00 \pm 29.88(22)$ \\
\hline Change from baseline & - & $26.79 \pm 28.81$ & $15.18 \pm 34.25$ & $12.96 \pm 35.61$ & $17.05 \pm 30.26(22)$ \\
\hline$P^{\mathrm{a}}$ & - & $<.0001$ & 0.0266 & 0.0697 & 0.0152 \\
\hline Distance & $57.68 \pm 33.84(28)$ & $80.18 \pm 24.71$ & $71.40 \pm 33.91$ & $64.33 \pm 37.01$ & $67.97 \pm 39.93(22)$ \\
\hline Change from baseline & - & $22.50 \pm 29.02$ & $13.72 \pm 27.84$ & $4.67 \pm 31.61(27)$ & $5.69 \pm 29.78(22)$ \\
\hline$P^{\mathrm{a}}$ & - & 0.0003 & 0.0147 & 0.4501 & 0.3803 \\
\hline Speed & $37.38 \pm 21.36(28)$ & $48.10 \pm 24.36$ & $44.53 \pm 27.46(28)$ & $43.20 \pm 31.52$ & $46.39 \pm 30.19(22)$ \\
\hline Change from baseline & - & $10.71 \pm 19.57$ & $7.14 \pm 21.90$ & $5.23 \pm 26.34(27)$ & $5.88 \pm 27.36(22)$ \\
\hline$P^{\mathrm{a}}$ & - & 0.0074 & 0.0958 & 0.3114 & 0.3249 \\
\hline Stair climbing & $44.20 \pm 33.15$ & $56.10 \pm 35.49$ & $55.66 \pm 37.03$ & $57.10 \pm 40.94(27)$ & $63.26 \pm 40.14(22)$ \\
\hline Change from baseline & - & $\begin{array}{l}11.90 \pm 30.00 \\
(28)\end{array}$ & $\begin{array}{l}11.46 \pm 39.29 \\
(28)\end{array}$ & $\begin{array}{l}13.58 \pm 37.22 \\
(27)\end{array}$ & $\begin{array}{l}18.56 \pm 35.21 \\
(22)\end{array}$ \\
\hline$P^{\mathrm{a}}$ & - & 0.0452 & 0.1345 & 0.0692 & 0.0220 \\
\hline
\end{tabular}

Values are mean \pm SD (n)

${ }^{\mathrm{a}} P$-values calculated by paired t-test

to probe generalizability of the global study results and examine whether patient outcomes may be differentially affected by practice- or population-based factors. Dedicated study of DES use among Japanese patients is required to investigate practice-related reasons for the outcomes observed. For example, intraprocedural use of intravascular ultrasound was not required or documented for purposes of the IMPERIAL study; however, it is commonly incorporated in Japanese endovascular practice and may have contributed to the excellent observed outcomes [17].

In conclusion, two-year results from the cohort of Japanese patients in IMPERIAL showed a numerically lower CD-TLR rate for Eluvia compared with Zilver PTX, and clinical outcome improvements sustained over time. This additional description of the Japanese cohort supports the applicability of the overall study conclusions to
Japanese patients with clinical characteristics similar to those represented in the study.

Acknowledgements The authors thank the following Boston Scientific employees for their assistance: Rieko Kuribayashi and Naoko Takahashi (clinical trial management) and Elizabeth J. Davis, PhD (medical writing).

Author Contributions Stefan Müller-Hülsbeck, Juan Diaz-Cartelle, and William A. Gray contributed to the overall study conception and design.

Osamu Iida, Yoshimitsu Soga, Daizo Kawasaki, Hiroyoshi Yokoi, Kimihiko Kichikawa, Masato Nakamura, and Takao Ohki contributed to data collection.

Osamu Iida guided development of the first draft of the manuscript.

All authors commented on previous versions of the manuscript and read and approved the final manuscript.

Funding This study was funded by Boston Scientific Corporation, Marlborough, MA, USA. Employees of and consultants to the funding 
Table 4 Improvement in EQ$5 \mathrm{D}$ health-related quality of life dimensions

\begin{tabular}{|c|c|c|c|c|}
\hline & Eluvia & Zilver PTX & Difference $[95 \% \mathrm{CI}]$ & $p$ \\
\hline \multicolumn{5}{|l|}{1 Month } \\
\hline Mobility & $48.2 \%(27 / 56)$ & $35.7 \%(10 / 28)$ & $12.5 \%[-9.6 \%, 34.6 \%]$ & 0.28 \\
\hline Self-care & $1.8 \%(1 / 56)$ & $3.6 \%(1 / 28)$ & $-1.8 \%[-9.5 \%, 5.9 \%]$ & $1.00^{\mathrm{a}}$ \\
\hline Usual activities & $19.6 \%(11 / 56)$ & $35.7 \%(10 / 28)$ & $-16.1 \%[-36.6 \%, 4.5 \%]$ & 0.11 \\
\hline Pain/discomfort & $44.6 \%(25 / 56)$ & $39.3 \%(11 / 28)$ & $5.4 \%[-16.9 \%, 27.6 \%]$ & 0.64 \\
\hline Anxiety/depression & $10.7 \%(6 / 56)$ & $17.9 \%(5 / 28)$ & $-7.1 \%[-23.5 \%, 9.2 \%]$ & $0.49^{\mathrm{a}}$ \\
\hline \multicolumn{5}{|l|}{6 Months } \\
\hline Mobility & $48.2 \%(27 / 56)$ & $21.4 \%(6 / 28)$ & $26.8 \%[6.7 \%, 46.8 \%]$ & 0.02 \\
\hline Self-care & $1.8 \%(1 / 56)$ & $0.0 \%(0 / 28)$ & $1.8 \%[-1.7 \%, 5.3 \%]$ & $1.00^{\mathrm{a}}$ \\
\hline Usual activities & $19.6 \%(11 / 56)$ & $32.1 \%(9 / 28)$ & $-12.5 \%[-32.7 \%, 7.7 \%]$ & 0.20 \\
\hline Pain/discomfort & $41.1 \%(23 / 56)$ & $28.6 \%(8 / 28)$ & $12.5 \%[-8.6 \%, 33.6 \%]$ & 0.26 \\
\hline Anxiety/depression & $8.9 \%(5 / 56)$ & $21.4 \%(6 / 28)$ & $-12.5 \%[-29.4 \%, 4.4 \%]$ & $0.17^{\mathrm{a}}$ \\
\hline \multicolumn{5}{|l|}{12 Months } \\
\hline Mobility & $40.0 \%(22 / 55)$ & $22.2 \%(6 / 27)$ & $17.8 \%[-2.6 \%, 38.1 \%]$ & 0.11 \\
\hline Self-care & $1.8 \%(1 / 55)$ & $0.0 \%(0 / 27)$ & $1.8 \%[-1.7 \%, 5.3 \%]$ & $1.00^{\mathrm{a}}$ \\
\hline Usual activities & $20.0 \%(11 / 55)$ & $33.3 \%(9 / 27)$ & $-13.3 \%[-34.0 \%, 7.4 \%]$ & 0.19 \\
\hline Pain/discomfort & $47.3 \%(26 / 55)$ & $25.9 \%(7 / 27)$ & $21.3 \%[0.2 \%, 42.5 \%]$ & 0.06 \\
\hline Anxiety/depression & $10.9 \%(6 / 55)$ & $11.1 \%(3 / 27)$ & $-0.2 \%[-14.6 \%, 14.2 \%]$ & $1.00^{\mathrm{a}}$ \\
\hline \multicolumn{5}{|l|}{24 Months } \\
\hline Mobility & $40.8 \%(20 / 49)$ & $27.3 \%(6 / 22)$ & $13.5 \%[-9.6 \%, 36.7 \%]$ & 0.27 \\
\hline Self-care & $4.1 \%(2 / 49)$ & $4.5 \%(1 / 22)$ & $-0.5 \%[-10.8 \%, 9.9 \%]$ & $1.00^{\mathrm{a}}$ \\
\hline Usual activities & $14.3 \%(7 / 49)$ & $31.8 \%(7 / 22)$ & $-17.5 \%[-39.3 \%, 4.3 \%]$ & $0.11^{\mathrm{a}}$ \\
\hline Pain/discomfort & $38.8 \%(19 / 49)$ & $40.9 \%(9 / 22)$ & $-2.1 \%[-26.8 \%, 22.5 \%]$ & 0.86 \\
\hline Anxiety/depression & $12.2 \%(6 / 49)$ & $18.2 \%(4 / 22)$ & $-5.9 \%[-24.5 \%, 12.6 \%]$ & $0.49^{\mathrm{a}}$ \\
\hline
\end{tabular}

${ }^{a} p$-values from 2 -sided Fisher's exact test body were involved in the design of the study, analysis, and interpretation of data and in writing the manuscript.

\section{Declarations}

Conflict of interest Osamu Iida reports consulting for Boston Scientific.Masahiko Fujihara reports consulting for Boston Scientific.Daizo Kawasaki reports consulting for Boston Scientific.Mori Shinsuke has no financial conflicts of interest to disclose.Hiroyoshi Yokoi reports consulting for Boston Scientific.Akira Miyamoto reports consulting for Boston Scientific.Kimihiko Kichikawa reports consulting for Boston Scientific.Masato Nakamura reports consulting for Boston Scientific.Takao Ohki reports consulting for Boston Scientific.Juan Diaz-Cartelle is an employee of and owns stock in Boston Scientific.William A. Gray serves as an advisor to Boston Scientific.Stefan Müller-Hülsbeck serves as a consultant and has received honoraria and travel grants from Boston Scientific, and has received fees from Terumo.Yoshimitsu Soga serves as an advisor to Boston Scientific.

Ethical Approval All procedures performed in studies involving human participants were in accordance with the ethical standards of the institutional and/or national research committee and with the 1964 Helsinki Declaration and its later amendments or comparable ethical standards. The study protocol was approved by the applicable Institutional Review Board (IRB), ethics committee, or research ethics board for each study site.
Informed Consent Informed consent was obtained from all individual participants included in the study.

Consent for Publication For this type of study, consent for publication is not required.

Open Access This article is licensed under a Creative Commons Attribution 4.0 International License, which permits use, sharing, adaptation, distribution and reproduction in any medium or format, as long as you give appropriate credit to the original author(s) and the source, provide a link to the Creative Commons licence, and indicate if changes were made. The images or other third party material in this article are included in the article's Creative Commons licence, unless indicated otherwise in a credit line to the material. If material is not included in the article's Creative Commons licence and your intended use is not permitted by statutory regulation or exceeds the permitted use, you will need to obtain permission directly from the copyright holder. To view a copy of this licence, visit http://creativecommons. org/licenses/by/4.0/.

\section{References}

1. Tepe G, Laird J, Schneider P, et al. Drug-coated balloon versus standard percutaneous transluminal angioplasty for the treatment of superficial femoral and/or popliteal peripheral artery disease: 12-month results from the IN.PACT SFA randomized trial. Circulation. 2015;131:495-502. 
2. Krishnan P, Faries P, Niazi K, et al. Stellarex drug-coated balloon for treatment of femoropopliteal disease: 12-month outcomes from the randomized ILLUMENATE pivotal and pharmacokinetic studies. Circulation. 2017;136:1102-13.

3. Rosenfield K, Jaff MR, White CJ, et al. Trial of a paclitaxelcoated balloon for femoropopliteal artery disease. N Engl J Med. 2015;373:145-53.

4. Thieme M, Von Bilderling P, Paetzel C, Karnabatidis D, Perez Delgado J, Lichtenberg M. The 24-month results of the lutonix global SFA registry worldwide experience with lutonix drugcoated balloon. JACC Cardiovasc Interv. 2017;10(16):1682-90.

5. Steiner S, Willfort-Ehringer A, Sievert H, et al. 12-month results from the first-in-human randomized study of the ranger paclitaxel-coated balloon for femoropopliteal treatment. JACC Cardiovasc Interv. 2018;11:934-41.

6. Steiner S, Schmidt A, Zeller T, et al. COMPARE: prospective, randomized, non-inferiority trial of high- vs. low-dose paclitaxel drug-coated balloons for femoropopliteal interventions. Eur Heart J. 2020;41:2541-52.

7. Dake MD, Ansel GM, Jaff MR, et al. Sustained safety and effectiveness of paclitaxel-eluting stents for femoropopliteal lesions: 2-year follow-up from the Zilver PTX randomized and single-arm clinical studies. J Am Coll Cardiol. 2013;61:2417-27.

8. Dake MD, Ansel GM, Jaff MR, et al. Durable clinical effectiveness with paclitaxel-eluting stents in the femoropopliteal artery: 5-year results of the zilver PTX randomized trial. Circulation. 2016;133:1472-83.

9. Kichikawa K, Ichihashi S, Yokoi H, et al. Zilver PTX postmarket surveillance study of paclitaxel-eluting stents for treating femoropopliteal artery disease in japan: 2-year results. Cardiovasc Intervent Radiol. 2019;42:358-64.

10. Müller-Hülsbeck S, Benko A, Soga Y, et al. Two-year efficacy and safety results from the imperial randomized study of the eluvia polymer-coated drug-eluting stent and the zilver PTX polymer-free drug-coated stent. Cardiovasc Intervent Radiol. 2021;44:368-75.
11. Ohki T, Yokoi H, Kichikawa K, et al. Two-year analysis of the Japanese cohort from the Zilver PTX randomized controlled trial supports the validity of multinational clinical trials. J Endovasc Ther. 2014;21:644-53.

12. Gray WA, Keirse K, Soga Y, et al. A polymer-coated, paclitaxeleluting stent (Eluvia) versus a polymer-free, paclitaxel-coated stent (Zilver PTX) for endovascular femoropopliteal intervention (IMPERIAL): a randomised, non-inferiority trial. Lancet. 2018;392:1541-51.

13. Song P, Rudan D, Zhu Y, et al. Global, regional, and national prevalence and risk factors for peripheral artery disease in 2015: an updated systematic review and analysis. Lancet Glob Health. 2019;7:e1020-30.

14. Soga Y, Fujihara M, Iida O, et al. Japanese patients treated in the IMPERIAL randomized trial comparing eluvia and zilver PTX stents. Cardiovasc Intervent Radiol. 2020;43:215-22.

15. Iida O, Soga Y, Urasawa K, et al. Drug-coated balloon versus uncoated percutaneous transluminal angioplasty for the treatment of atherosclerotic lesions in the superficial femoral and proximal popliteal artery: 2-year results of the MDT-2113 SFA Japan randomized trial. Catheter Cardiovasc Interv. 2019;93:664-72.

16. Albrecht T, Ukrow A, Werk M, et al. Impact of patient and lesion characteristics on drug-coated balloon angioplasty in the femoropopliteal artery: a pooled analysis of four randomized controlled multicenter trials. Cardiovasc Intervent Radiol. 2019;42:495-504.

17. Iida O, Soga Y, Urasawa K, et al. Drug-coated balloon vs standard percutaneous transluminal angioplasty for the treatment of atherosclerotic lesions in the superficial femoral and proximal popliteal arteries: one-year results of the MDT-2113 SFA japan randomized trial. J Endovasc Ther. 2018;25:109-17.

Publisher's Note Springer Nature remains neutral with regard to jurisdictional claims in published maps and institutional affiliations. 